\title{
The Impacts of International Service Learning on a Host Community in Kenya: Host Student Perspectives Related to Global Citizenship and Relative Deprivation
}

\author{
Elizabeth Mogford \\ Western Washington University \\ Christopher J. Lyons \\ University of New Mexico
}

\begin{abstract}
:
Despite recent calls, research on ISL has focused almost exclusively on learning outcomes for global North students. We know comparatively less about how ISL programs may impact the knowledge and perceptions of student participants from host countries in the global South. We examine learning outcomes for Kenyan students who interact with visiting students from a U.S. university. Using an original survey and a case-control design, we compare the responses of students from an ISL partner school with those of students in a nearby control school to explore how program participation influences ideas about global citizenship, viewpoints about the United States, and feelings of relative deprivation. Results point to the complexity of ISL programs and their impact on host country participants. On the one hand, we find that ISL partner students show higher levels of global citizenship than control group students. On the other hand, ISL partner students are more likely than the control group to agree with unrealistically positive views of the United States and report greater feelings of relative deprivation. We apply Allport's intergroup contact theory to interpret these findings and reflect on future directions.
\end{abstract}

\section{Introduction}

A growing number of colleges and universities have committed to international study as a means to foster global citizenship and civic responsibility among their students (Hartman \& Kiely, 2014a). Evaluations suggest that study abroad programs provide students with life changing experiences that can transform them into more conscientious and socially responsible global citizens (Nelson \& Klak, 2012). Short-term study abroad trips include International Service Learning (ISL) programs in which global North students visit global South communities. Ideally, ISL courses are rooted in experiential and service learning pedagogy and focus on direct interaction, cross-cultural dialogue, community-based service activities, and reflection as means to reach an understanding of global and intercultural issues and how they connect to students' responsibility as citizens (Bringle \& Hatcher, 2011, p. 19).

Extensive research on the impacts of ISL focuses almost exclusively on growth among global North students in areas such as knowledge production, intercultural competence, civic engagement, 
and future goals (Nelson \& Klak, 2012; Fry, Paige, Jon, Dillow, \& Nam, 2009; Tarrant, Rubin \& Stoner, 2014; Tarrant, Rubin \& Stoner, 2015; Tonkin, 2004). Research demonstrates that ISL provides opportunities for students to gain a deeper understanding of economic disparities, structural forces that affect poverty, and the uneven distribution of wealth (Kiely, 2005; Kiely, 2011; Larsen, 2014; Lutterman-Aguilar \& Gingerich, 2015). In contrast, similar inquiries are seldom made about the global South communities with which Western students engage (Bortolin, 2011; Hartman, Paris \& Blache-Cohen, 2014; Larsen, 2016). Only recently have scholars begun to look at the experiences of global South community members themselves, particularly in the form of qualitative case studies (see, for example, the edited anthology by Larsen, 2016). But unseen are studies that examine the equivalent outcomes we see in the decades of student-centered literature, that is, outcomes related to growth in global citizenship, intercultural learning, and knowledge of global hierarchies and structural inequities.

This lacuna remains despite a growing presence of critical frameworks calling for more focus on global South communities. Hartman and Kiely (2014b), for instance, identify the imbalance towards the Western student experience in ISL programs and call for reframing ISL as Global Service Learning (GSL) or Fair Trade Learning to better incorporate all participants in every stage, from program conceptualization and design to implementation and evaluation. GSL's focus on hegemony, axes of power and privilege, and structural inequities inherent in study abroad, and its recognition that GSL occurs in a growing market of global volunteerism denotes that ISL program leaders cannot blithely assume that their best intentions will result in good outcomes for communities. While concerns related to community impact are not new to ISL practitioners, GSL represents a needed shift in attention towards the host community. Part of this shift is a recognition that ISL practitioners need to engage in more empirically based and theoretically grounded research about the potential promises and pitfalls communities face when they host ISL programs.

Heeding this call, our study examines data from an original survey that gauges potential impacts on community partners of a faculty-led ISL program that has brought small groups of U.S. students to rural Kenya since 2010. Paralleling the principles of GSL, the cultural exchange is designed in close collaboration with the Kenyan hosts, forefronting community voice and providing co-learning and exchange for all participants. The goal is to nurture lasting cross-cultural relationships built on interdependence (Dear \& Howard, 2016) and mutual respect.

We assess what impact, if any, intercultural collaboration with students from the US has on Kenyan students' ideas about global citizenship, knowledge of and orientation towards other cultures, and sense of their economic and social standing relative to the US. We employ a case/control design to assess the effect of our ISL program on Kenyan students. Specifically, we compare survey responses from students in a boarding school that is one of the primary partners of the ISL program and those from students in a similarly situated academy that does not host an ISL program or have contact with groups from the global North.

Past research leads us to expect that ISL programs can result in transformational and positive experiences for everyone involved. Deep friendships often develop, and these connections can facilitate learning about new cultures, languages, and ways of being (Larsen, 2016; MacDonald \& Vorstermans, 2016). However, there are reasons to suspect that intercultural contact may engender 
more complicated impacts as well. The U.S. students' presence and patterns of consumption may contribute to feelings of dissatisfaction and deprivation among community members-a phenomenon known as the "demonstration effect" (Schroeder, Wood, Galiardi, \& Koehn, 2009; Wood, Banks, Galiardi, Koehn, \& Schroeder, 2011). Although U.S. students often feel economically burdened based on their student status and financial indebtedness (indeed, many of them go to great lengths to fund their travel), the mere fact that they are able to fly on an airplane halfway across the world may signify unfathomable wealth to their local counterparts. Even when U.S. students make concerted efforts to be modest in self-presentation, their clothing, smartphones, cameras, backpacks, and fancy water bottles all suggest abundance and may contribute to a sense of relative deprivation among community members.

To make sense of these potentially disparate impacts, we consult the predominant perspective for understanding intergroup relations and stereotypes: the intergroup contact hypothesis developed by Allport (1954). Applied to an intercultural exchange program, contact theory suggests that under certain circumstances, community members' interaction with students from the US can reduce myths and stereotypes across groups. However, according to the theory, not all cross-cultural contact will reduce stereotypes or biases. Intergroup contact theory draws attention to the potential complications related to contact between actors with asymmetrical status, an arguably inescapable condition ascribed to U.S. and Kenyan students due to global socio-economic hierarchies. Drawing upon these insights, we further explore how students in two Kenyan academies vary in their assessments of U.S. culture and sense of relative deprivation. Our study thus provides initial insight into the potential consequences of ISL programs on individuals in host communities in the global South.

\section{Impacts of ISL on Host Communities}

Although much of the research on ISL has focused on the many benefits of learning in an international context, growing critical consciousness has begun to illuminate numerous challenges ISL presents to host community members in the global South. Critiques describe potential negative economic impacts (Baldwin, Mohamed, \& Tembe, 2016; Hernández, 2016; MacDonald \& Vorstermans, 2016; O’Sullivan \& Smaller, 2016; Wood, Banks, Galiardi, Koehn, \& Schroeder, 2011) as well as those related to student conduct and the imbalanced focus on the growth of students from the global North. Student-related critiques are particularly salient for the focus of this study. Research describes global South community members experiencing discomfort with some student behaviors, such as dressing inappropriately, not providing proper respect to elders, physical contact in public, and refusing to eat food that was offered (Kozak \& Larsen, 2016; Schroeder et. al., 2009). Western visitors often hold unconscious stereotypes and even racist assumptions about their host countries, which can lead to cross-cultural misunderstandings (Heron, 2016). Students sometimes express entitlement, believing that since they are on a trip presumably to help others, they deserve special treatment (Arends, 2016). Deeply embedded biases held by students, i.e., of being the helper, or of being more knowledgeable than or superior to their hosts, can be internalized by community members and can reinforce stereotypes that devalue the global South vis-à-vis the North within the community (Larsen, 2016). Students may exoticize the host country and approach it as a place they can fix (Jorgenson, 2016). Students can also contribute to a sense of relative deprivation through what the tourism literature has called the demonstration effect: numerous cues-including what visiting students wear, the photos from home they share, and going on excursions or eating at 
upscale restaurants — can signal the vast material divide between groups (Kohen, 2009; Larkin, 2016). Among the critiques of ISL is the imbalanced focus on student growth as the primary goal of many programs. This can result in an asymmetrical relationship between the host community and the students, wherein student learning occurs through interaction with the non-subjective "other" (the host) (Larsen, 2016), and can lead to blindness towards the effects (pre-, during, and post-trip) of study abroad on host communities.

In spite of these challenges, the limited number of studies conducted with hosts from global South communities suggests that the benefits outweigh the costs and that hosts prefer that programs continue (Kozak \& Larsen, 2016). Among the benefits communities highlight are economic stimuli (Heron, 2016; Kozak \& Larsen, 2016; Larsen, 2016; Nelson \& Klak, 2012; O’Sullivan \& Smaller, 2016; Schroeder et al., 2009; Smedley, 2016; Wood et al., 2011) and skill acquisition (Kozak \& Larsen, 2016; Larsen, 2016). Additionally, research highlights that ISL provides an unparalleled opportunity for coeducation and deeply rewarding cross-cultural exchange and friendship. Community members describe pride in sharing their culture and way of living with ISL students (Kozak \& Larsen, 2016; Nelson \& Klak, 2012). In one study, the sense of pride was accompanied by confianza, or trust/confidence in the partnership (Reynolds, 2014). For many community members who may not travel abroad, hosting a student can be a way to experience another culture indirectly and is a major motivation for participating in ISL programs (MacDonald \& Vostermans, 2016). Community members recount how hosting enhances their own global understandings and perspectives and describe having stereotypes about Americans altered through their interactions (Kozak \& Larsen, 2016). One community host of an ISL program spoke of how hearing the stories of visitors dispelled myths he held about the idealized image of life in America, in which everyone is a millionaire and nobody has problems (O'Sullivan \& Smaller, 2016). Teaching aspects of their own culture to students, from dancing and cooking to language acquisition, can also result in increased pride in their country and way of life. Friendship, camaraderie, and trust that develop over long-term partnerships are powerfully rewarding elements of ISL for host community members.

\section{Global Citizenship and Intercultural Contact Theory}

ISL programs are designed to facilitate global citizenship, wherein student participants gain intercultural competence, a broadened understanding of global processes, international perspectives, personal growth, and the opportunity to examine their own belief systems (Whitehead, 2015). Intercultural knowledge is an element of global citizenship that involves challenging one's preconceived notions and stereotypes about the host and visiting country. Coeducation between hosts and students, with an intentional focus on mutual learning about each other's respective cultures and lives, provides a mechanism to achieve intercultural knowledge among both Western students and host country participants.

Previous work (Paik, Ganley, Luschei, Witenstein, Shimogori, \& Truong, 2015) highlights Allport's (1954) contact hypothesis of intergroup relations as a useful framework for understanding how intercultural contact and coeducation can influence participants' global consciousness and intercultural knowledge. Put simply, Allport's theory assumes that, under certain conditions, contact between groups should improve intergroup knowledge and understanding, and hence decrease misinformation, out-group prejudice and stereotypes. Allport (1954) stipulates four conditions that determine the benefit of contact. First, cross-cultural interactions must be managed and supported 
by social and institutional authorities. Second, groups should work together towards a common goal(s) in, third, a mutually cooperative, non-competitive environment. Fourth, there should be equal status between the groups in the situation (Allport, 1954; Paik et al., 2015; Pettigrew \& Tropp, 2005). Importantly, not all contact will lead to improved intergroup understanding. Deficiencies in any of the four conditions above can undermine the benefit of contact, and in some cases may even reinforce misinformation and intergroup bias (Pettigrew \& Tropp, 2005).

Paik et al. (2015) extend Allport's theory to situations involving cross-cultural, international interactions. Intercultural contact theory provides a way to consider how the contact brought about through an ISL program potentially influences individuals' perspectives about an unfamiliar culture as well as perspectives regarding one's social position in relation to the other culture. Cross-cultural contact that adheres to the four conditions outlined in Allport's theory can result in reduced prejudices, biases, and stereotypes, leading to greater understanding of and appreciation for different cultures - in other words, global citizenship.

However, a challenge in intercultural contact is achieving equal status between the groups. Generally, research on this condition attempts to equalize status within a situationally defined relationship. In an ISL context in which students from the global North partner with students from the global South, coeducation and joint program activities go some way to satisfy the condition of equal status within a relationship. Yet, Western students bring ascribed statuses based on global hierarchies that often exceed any situationally produced identities. Access to financial resources, educational opportunities, ability to travel, and many other factors may be highly discrepant between groups. Thus, insofar as ISL programs visiting the global South violate Allport's condition of equal status, the programs run the risk of not reducing, and perhaps even reinforcing, intercultural stereotypes. Despite the centrality of this concern in GSL scholarship, we are not aware of any research that directly assesses these questions for host community members.

\section{Program Context}

We explore how participation in an ISL program influences host student's sense of global citizenship and perceptions of relative deprivation. The program studied here emerged out of a collaborative relationship between Kenyan community members and individuals affiliated with a U.S. state university and a small non-profit organization that supported programs in the rural community. The initial partnership dates back to 2004, when an employee of the U.S. university was introduced to a Kenyan community leader by a mutual Kenyan friend who lived in the United States. The community leader was also the founder of an all girls' boarding school (hereafter referred to as the Academy), and he invited the university to develop a global service learning program in the village. In 2007, the abovementioned university employee recruited three faculty members (including the lead author of this paper) to form an ISL Faculty Fellows group that met bimonthly from 20072009 to conceptualize the academic program, in collaboration with their Kenyan partners. Prior to initiating the program, different members of this group visited Kenya three times to conduct community-driven needs assessments and nurture relationships. Beginning in 2010, faculty began accompanying students to Kenya for a quarter-long ISL course, with 11-13 students per cohort, and successfully completed six trips between 2010 and 2018. The lead author of this paper has been one of the faculty members on each of these trips. 
The academic program aligns closely with the principles of GSL. It is rooted in collaborative, sustainable relationships with coeducation as a fundamental goal. It is designed with care to avoid academic tourism or a "feel good," "save the world" experience for Western students and maintains a commitment to deep and personal learning for all participants. The program prioritizes the mutuality, respect, and long-term nature of partner relationships and emphasizes working in collaboration with community members to meet their self-identified short- and long-term goals. The Academy, one of the primary community partners, is a Seventh Day Adventist (SDA) private allgirls' boarding school with approximately 130 secondary school student residents. ${ }^{\text {i }}$

Although the program was not developed using intercultural contact hypothesis as a framework, we outline aspects of the program according to their alignment with the four criteria of the theory. Since our study participants are the young women at the Academy, we focus specifically on the ISL program's partnership with the Academy.

Support from social and institutional leadership. Institutions in both Kenya and the US enthusiastically support the ISL partnership. The Academy's leadership trio (the founder, director, and principal) are strong advocates of the partnership. In fact, written in bold face on the entry sign to the Academy is the statement "in collaboration with [the U.S. institution]" for all passers-by to see. The Academy faculty, students and parents boast of the relationship with the U.S. university.

Groups should work together towards common goals in a mutually cooperative, non-competitive environment. Many of the formal and informal activities that take place during the five-week stay in the village help to reinforce these two conditions. The U.S. students often spend several hours per day at the Academy, attending classes to learn about the local education system, offering workshops and guest lectures in the classes, studying Swahili and the local language, attending after-school clubs and sports activities, and sometimes joining the young women during weekend religious services and dance parties/entertainment.

A core part of the ISL curriculum is an after-school peer-education series referred to as "cohorts." Cohorts serve both the second and third conditions of intercultural contact theory by bringing Academy and U.S. students together cooperatively to achieve common goals. All of the young women at the Academy form groups, each led by a student from the US. Frequent cohort workshops focus on topics selected by students, such as "racism," "relationships," "body image," "career planning," and "stress management." The sessions are designed and prepared by the Western students with input from the Academy students and emphasize creative, experiential co-learning.

Relationships are also strengthened in a non-competitive, cooperative way through mutual performance and by sharing music and talent throughout the trip. This culminates in a talent show at the end of the visit. A goal of mutual performance is reciprocal cultural sharing, thus avoiding "othering" host country partners in alienating ways (Nelson \& Klak, 2012). Another mutual activity is community work, where Western and Academy students jointly engage in community service throughout the village.

The final criterion of the contact hypothesis, equal status in the relationship, is arguably the most difficult to achieve. To sensitize Western students to the complexities of inequality, the GSL course begins with a rigorous 40 -hour pre-trip orientation on the U.S. campus, where students study 
global disparities in power and privilege resulting from centuries of colonialism and exploitation. The curriculum explores problems in international development arising from the hegemony between the global North and South, focuses on challenging a charity mentality, and unpacks unconscious stereotypes U.S. students have about Kenya. Because inequities also exist within America, the curriculum includes exercises on identity, power, and privilege among the U.S. students. Students are prepared by engaging in reflective activities, having open conversations about equitable relationships, problematizing foreign aid and voluntourism, and discussing strategies to mitigate negative impacts (similar to Galiardi \& Koehn, 2012).

Once in Kenya, the program works towards reciprocity and mutuality in relationships with community members and Academy students. One element of this is adhering to a dress code that conveys respect. Academy students are in uniform, and the faculty dress formally. Hence, the U.S. students do not wear t-shirts, shorts, tank tops, or jeans. This dress code sets the students apart from the image of many other student or tourist groups, and community members repeatedly report that they are relieved and pleased that the visitors are not scantily clad or wearing worn-out clothing. Village elders, in particular, appreciate aloud that they don't need to be concerned about the negative influence the U.S. students' appearance may have on local youth. The program also focuses on reciprocity through education (Dear \& Howard, 2016), achieved by knowledge building and information exchange, challenging stereotypes, and committing to a long-term relationship with the community.

One of the most meaningful aspects of the partnership is providing all participants the opportunity to examine their motivations, preconceptions, and assumptions about each other's respective culture. To this end, shared culture sessions are held with community members (young and old, men and women) and the U.S. students learn as much of the local language as possible. Finally, the program includes an "American stereotype busting" panel session with all 130 students at the Academy. Over the years it has been observed that students at the Academy have a very rosy view of life in the US, assuming that there is no poverty, racism, or gender discrimination. The students often wistfully describe how their lives would be perfect if they could move to America. Without denying that disparities exist between the global North and global South, the stereotype busting session provides factual information about unjust disparities and social problems within the US. This information is intended to counter many of the overly positive assumptions about life in America, and it often comes as a surprise to the Academy students. The program thus encourages all participants, including community partners, to challenge stereotypes and expectations.

Despite efforts to equalize relationships programmatically with the young women at the Academy and with other community members, U.S. students bring into the environment ascribed characteristics that potentially transcend attempts to create symmetry. One consequence of not meeting Allport's condition of equal status in a GSL program that has strong institutional support is that intercultural contact might not only reinforce stereotypes, but also increase perceptions of relative deprivation as Academy students interact with relatively wealthy students from the global North. Reference group theories in sociology (Hyman \& Singer, 1968; Merton \& Kitt, 1950) provide some insight into how this may occur. Reference group theories anchor self-appraisals and perceptions of self to the significant others with whom individuals interact. Strong institutional support for the intercultural exchange raises the likelihood that Academy students may begin to shift 
their reference group to include their Western counterparts, comparing themselves with the Western students with whom they have built relationships. We do not claim that an intercultural exchange program necessarily leads to dramatic shifts in reference categories for students; clearly, the most important reference group for one's sense of self is likely to be within one's country. However, even subtle shifts brought about by coeducational experiences can challenge one's status in relation to the other.

Given the foregoing discussion, we anticipate that program participation may lead to a number of possible outcomes for Academy students. On the one hand, we expect that students who participate in the ISL program will espouse a greater sense of global citizenship compared to students in the control group school because of their exposure to broadened cross-cultural perspectives, increased first-hand knowledge of life in another country, and deep friendships with U.S. students. Coeducation and continual exposure to new perspectives should expand the Academy students' worldviews. On the other hand, the association between program participation and intercultural knowledge and feelings of relative deprivation may be more complicated. We see at least two possible patterns here. The most optimistic possibility is that the program's emphasis on stereotype busting may be effective and lead Academy students to have more realistic impressions of life in the US. Alternatively, Allport's contact perspective raises the possibility that contact between individuals from groups with asymmetrical global status may reinforce Kenyan students' stereotypes about social, economic, and cultural realities of the US. Moreover, asymmetry in economic status between Kenyan and Western students may bring about a sense of relative deprivation that reinforces global scripts about the North/South axis of material wealth.

\section{Data and Methods}

To assess these possible relationships, we employ a case/control design, administering a survey to the Academy and a control school. ii The control school was selected to be as similar to the Academy as possible, with the exception of never hosting visitors from the global North. According to the principal of the control school, the day we administered the survey was likely the first time that many of the students had ever met a Westerner. Like the Academy, the control school is a Seventh Day Adventist private all-girls' boarding school; they are located in the same rural district.

The lead author administered the survey in English ${ }^{\mathrm{iii}}$ during class time to students at the Academy and control school. . Although participation was voluntary, all students offered the survey chose to participate. The final sample size is 260, with 119 Academy and 141 control school responses.

We focus our analyses on four groups of response variables: six items that measure ideas about global citizenship, 13 that measure beliefs in commonly-held stereotypes and related to general attitudes about the US, and four that gauge how students view their economic and cultural standing or sense of relative deprivation. We developed these items based on lived experiences with the Academy students and interviews we had conducted at the Academy during previous visits, starting in 2011. Thus, our selection of U.S. stereotype items reflects those that we found particularly prevalent. 
Our main independent variable, Academy, captures differences, if any, in responses between the treatment group (the Academy) and the control group. Although students from the control group and the Academy are similarly situated, we control for eight factors to account for other differences between students that might influence responses. Form is a series of four dummy variables that denote the student's academic class, with Form One as the reference category. Religion is coded 1 for Seventh Day Adventist and 0 for other religions ; Guardian denotes by whom the student was raised, coded 1 for mother and/or father and 0 for any other guardian (relatives or other); Polygamy refers to the student's father's number of wives, coded 1 if the father has multiple wives and 0 if he has 1 or is not married; and Pay Fees is a proxy for wealth referring to whether the student has been sent home from school to collect fees, coded 1 if yes and 0 if no. We created scales using confirmatory factor analysis with rotated component matrices for measures of household wealth and media access. The wealth scale, Wealth, is a simplified version of the Demographic and Health Survey (DHS) wealth index (Rutstein \& Johnson, 2004), based on questions related to the house in which the students grew up, such as whether the walls are brick or mud, what material the roof is constructed from, and whether there is indoor plumbing (alpha $=.61)$. Five media access variables loaded onto two components: E-media, referring to access to electronics (computer, Facebook, mobile phone; alpha $=.66)$ and $T V$, referring to access to Television (alpha $=.69)$.

All items are measured with a 5-response ordinal scale, from strongly disagree to strongly agree, with "not sure" coded as the middle value. The one exception is the question that asks whether students prefer Western culture over Kenyan culture (Western or Kenyan Culture), which is coded 0 for Kenya and 1 for the west. Although we explored scaling responses, low alpha scores preclude the use of data reduction; we thus examine responses separately. We estimate a series of ordered logit regressions for these responses and estimate logistic regressions for Western or Kenyan Culture.

\section{Findings}

Table 1 displays the results of two tailed t-tests comparing Academy and control school means, standard deviations, and the percentage difference between the means. Although the Academy and control school are similar on most indicators, small differences exist for Polygamy, Guardian, Religion, Form 1, and Pay Fees. To account for potential effects, we control for these and other covariates in the models that follow.

Table 1. Descriptive statistics of study variables.

\begin{tabular}{|c|c|c|c|c|c|}
\hline & \multicolumn{2}{|c|}{ Academy } & \multicolumn{2}{|c|}{ Control } & \multirow[b]{2}{*}{ T-Test } \\
\hline & mean & s.d. & mean & s.d. & \\
\hline Global Citizenship Measures & & & & & \\
\hline $\begin{array}{l}\text { I respect the cultural values and practices of others even when they are } \\
\text { different from my own (Respect Other Cultures) }\end{array}$ & 4.68 & 63 & 4.46 & .94 & $*$ \\
\hline I am open to having my beliefs and values challenged (Challenge Values) & 3.90 & 1.39 & 4.00 & 1.20 & \\
\hline $\begin{array}{l}\text { I have knowledge about the culture of at least one country other than Kenya } \\
\text { (Know Cultures) }\end{array}$ & 3.96 & 1.31 & 3.75 & 1.24 & \\
\hline $\begin{array}{l}\text { I am comfortable interacting with people from other countries outside of } \\
\text { Kenya (Comfort Interacting) }\end{array}$ & 4.59 & .91 & 4.38 & .97 & \\
\hline I am able to see the world through someone else's eyes (See the World) & 3.40 & 1.55 & 2.90 & 1.51 & $* *$ \\
\hline I am good at making friends with people from different cultures and countries & 4.59 & .77 & 4.36 & .95 & $*$ \\
\hline
\end{tabular}

(Make Int. Friends)

U.S. Stereotype Measures 
I believe everyone in America has a home (U.S. Home)

I believe men and women in America have equal opportunities in employment (U.S. Equal Work)

I believe the lifestyles and people I see on American TV programs accurately represent how life is really lived in America (U.S. TV Real)

I believe everyone in America has enough money to buy whatever they want (U.S. Money)

I believe children in America take care of parents into old age (U.S. Old Age)

I believe racism (treating people badly because they are not white) is not a problem in America today (U.S. No Racism)

I believe finding jobs is easy in America (U.S. Easy Job)

I believe there is a lot of poverty in America (U.S. Poverty)

I believe that there are slums in America (U.S. Slums)

I believe HIV/AIDS is a health problem in America (U.S. HIV)

I believe Americans would judge me based on my race/skin color (U.S. Judge

Race)

Opinions of U.S. Life and People

Do you have a good or bad view of American people? $(1=$ very bad; $5=$ very good) (U.S. Good People) good) (U.S. Good Live)

\section{Relative Deprivation Measures}

Seeing wealth of mzungus makes me think about material things I want but don't have (Mzungu Wealth)

I am not happy or fulfilled because I need more money (Lack Money)

I have all the material things I need to be happy in life (Have Material)
Do you think America is a good or a bad place to live? $(1=$ very bad; $5=$ very

$\begin{array}{lllll}2.67 & 1.28 & 2.61 & 1.06 & \\ 3.10 & 1.48 & 2.97 & 1.42 & \\ & & & & \\ 3.74 & 1.23 & 3.46 & 1.37 & \\ & & & & \\ 2.23 & 1.34 & 2.09 & 1.14 & * * \\ & & & & * * \\ 3.29 & 1.33 & 3.06 & 1.24 & \\ 3.47 & 1.41 & 3.01 & 1.42 & \\ & & & & \\ 3.32 & 1.44 & 2.75 & 1.34 & \\ 2.20 & 1.16 & 2.36 & 1.14 & \\ 3.45 & 1.26 & 3.43 & 1.19 & \\ 3.33 & 1.31 & 3.40 & 1.33 & \\ 2.64 & 1.51 & 2.91 & 1.39 & \\ & & & & \\ & & & & \\ 4.53 & .71 & 4.04 & .93 \\ & & & & \\ 4.54 & .73 & 4.25 & .88 \\ & & & & \\ 3.74 & 1.57 & 3.45 & 1.51 & \\ & & & & \\ 2.69 & 1.58 & 2.48 & 1.44 & \\ & 1.57 & 2.94 & 1.58 & \\ & & & & \\ & & & \end{array}$

\begin{tabular}{|c|c|c|c|c|c|}
\hline $\begin{array}{l}\text { Control variables } \\
\text { E-Media }\end{array}$ & -.01 & 1.01 & .01 & .99 & \\
\hline TV & -.06 & 1.00 & .05 & 1.00 & \\
\hline Wealth & -.04 & 1.02 & .04 & .99 & \\
\hline Pay fees & .74 & .44 & .58 & .50 & $* *$ \\
\hline Form1 & .17 & .38 & .29 & .46 & $*$ \\
\hline Form2 & .19 & .40 & .19 & .40 & \\
\hline Form3 & .32 & .47 & .24 & .43 & \\
\hline Form4 & .32 & .47 & .27 & .45 & \\
\hline $\begin{array}{l}\text { Religion }(0=\text { other religions; } 1= \\
\text { Seventh Day Adventist })\end{array}$ & 1.80 & 1.09 & 1.46 & .88 & $* *$ \\
\hline $\begin{array}{l}\text { Guardian }(0=\text { other friend/relative; } 1= \\
\text { mom and/or dad })\end{array}$ & .81 & .39 & .91 & .28 & $*$ \\
\hline Polygamy $(0=$ no; $1=$ yes $)$ & .25 & .43 & .13 & .34 & $*$ \\
\hline
\end{tabular}

Table 2 shows the results of a series of ordered logit models for the six measures of global citizenship. Although we find no statistically significant differences in the responses for openness to having values and beliefs challenged and knowledge of the culture of another country between the Academy and the control school, we do find significant differences for the other four measures. 
Table 2. Ordinal logit models for measures of global citizenship.

\begin{tabular}{|c|c|c|c|c|c|c|c|c|c|c|c|c|c|c|c|c|}
\hline \multirow[b]{3}{*}{ Academy (vs } & \multicolumn{3}{|c|}{$\begin{array}{c}\text { Respect Other } \\
\text { Cultures } \\
\end{array}$} & \multicolumn{2}{|c|}{$\begin{array}{c}\text { Challenge } \\
\text { Values }\end{array}$} & \multicolumn{2}{|c|}{$\begin{array}{c}\text { Know } \\
\text { Cultures }\end{array}$} & \multicolumn{2}{|c|}{$\begin{array}{c}\text { Comfort } \\
\text { Interacting } \\
\end{array}$} & \multicolumn{3}{|c|}{$\begin{array}{l}\text { See the } \\
\text { World }\end{array}$} & \multicolumn{3}{|c|}{$\begin{array}{c}\text { Make Int. } \\
\text { Friends } \\
\end{array}$} & \\
\hline & B & SE & & B & SE & B & SE & B & SE & & B & SE & & B & SE & \\
\hline & & & & & & & & & & & & & & & & \\
\hline Control) & .77 & .31 & $* *$ & -.01 & .25 & .34 & .25 & .69 & .30 & $* *$ & .50 & .25 & $* *$ & .57 & .28 & $* *$ \\
\hline E-media & .38 & .39 & & -.43 & .34 & .02 & .32 & -.10 & .39 & & .29 & .32 & & .05 & .36 & \\
\hline TV & -.01 & .18 & & .10 & .15 & .24 & .15 & .26 & .17 & & .26 & .15 & $*$ & .15 & .16 & \\
\hline Wealth & -.06 & .16 & & .02 & .14 & .09 & .14 & -.06 & .16 & & -.14 & .14 & & -.04 & .15 & \\
\hline Pay Fees & .16 & .18 & & -.17 & .15 & .00 & .15 & .08 & .17 & & -.07 & .15 & & .07 & .17 & \\
\hline Form $2^{1}$ & -.95 & .55 & $*$ & .33 & .45 & .43 & .43 & .18 & .50 & & -.31 & .43 & & -.61 & .48 & \\
\hline Form $3^{1}$ & -1.10 & .53 & $* *$ & .31 & .44 & .67 & .43 & .32 & .50 & & .04 & .40 & & -.46 & .48 & \\
\hline Form $4^{1}$ & -.71 & .55 & & -.26 & .44 & .41 & .44 & -.10 & .52 & & -.12 & .43 & & -.56 & .49 & \\
\hline Religion & .47 & .32 & & -.27 & .27 & -.09 & .27 & -.24 & .32 & & -.35 & .27 & & -.03 & .30 & \\
\hline Guardian & .20 & .31 & & .08 & .27 & -.09 & .26 & .11 & .30 & & -.18 & .26 & & -.03 & .29 & \\
\hline Polygamy & -.75 & .37 & $* *$ & .39 & .35 & .51 & .34 & .19 & .38 & & .64 & .33 & $*$ & .02 & .36 & \\
\hline /cut1 & -4.03 & .68 & & -2.71 & .45 & -2.01 & .45 & -3.31 & .58 & & -1.45 & .41 & & -4.29 & .67 & \\
\hline /cut2 & -2.98 & .55 & & -1.85 & .42 & -.78 & .41 & -2.30 & .50 & & -.18 & .40 & & -2.91 & .51 & \\
\hline /cut3 & -2.57 & .52 & & -1.61 & .42 & -.60 & .41 & -2.08 & .49 & & .04 & .40 & & -2.60 & .50 & \\
\hline /cut4 & -.65 & .48 & & -.08 & .41 & 1.08 & .42 & -.42 & .46 & & 1.06 & .40 & & -.76 & .46 & \\
\hline $\mathrm{N}$ & & & & 23 & & 24 & & 23 & & & 23 & & & 24 & & \\
\hline iv & 241 & & & 7 & & 1 & & 9 & & & 8 & & & 1 & & \\
\hline
\end{tabular}

Academy students are much more likely to agree that they respect the cultural values and practices of others, are more comfortable interacting with people from other countries, can see the world through another culture's perspective, and feel skilled at making cross-cultural friendships. For example, the odds of selecting a higher ordinal response for respecting the cultural values and practices of others - that is, more strongly agreeing with the statement-is more than two times greater [ $\exp (.768)=$ OR of 2.17] for Academy students compared to the control school. The odds ratios for the other responses, though somewhat smaller, are still substantial $(\mathrm{OR}=1.99,1.65$, and 1.77 for comfort interacting, see the world, and making friends, respectively).

We next examine adherence to various stereotypes about U.S. culture and overall impressions of the US as a place to live and Americans as people. We estimate separate ordered logit models for 13 statements; to conserve space we display in Table 3 only the results for the six responses for which we find significant differences between Academy students and the control school. Results for the other models are shown in Appendix A.

Table 3. Ordinal logits models for measures of stereotypes and attitudes about US.

\begin{tabular}{|c|c|c|c|c|c|c|c|c|c|c|c|c|c|c|c|c|c|}
\hline & \multicolumn{3}{|c|}{ U.S. TV Real } & \multicolumn{3}{|c|}{ U.S. No Racism } & \multicolumn{2}{|c|}{ U.S. Judge Race } & \multicolumn{3}{|c|}{ U.S. Easy Job } & \multicolumn{3}{|c|}{ U.S. Good People } & \multicolumn{3}{|c|}{ U.S. Good Live } \\
\hline & B & SE & & B & SE & & B & SE & B & SE & & B & SE & & B & SE & \\
\hline $\begin{array}{l}\text { Academy } \\
\text { (vs Control) }\end{array}$ & .52 & .25 & $* *$ & .75 & .25 & $* *$ & -.42 & .25 & .76 & .25 & $* *$ & 1.18 & .27 & $* * *$ & .70 & .28 & $* *$ \\
\hline
\end{tabular}




\begin{tabular}{|c|c|c|c|c|c|c|c|c|c|c|c|c|c|c|c|c|c|c|}
\hline E-media & -.10 & .32 & & -.24 & .31 & & .14 & .31 & & -.06 & .30 & & .47 & .35 & & .80 & .34 & $* *$ \\
\hline $\mathrm{TV}$ & .23 & .14 & & -.21 & .14 & & .17 & .14 & & .00 & .14 & & -.01 & .15 & & -.02 & .16 & \\
\hline Wealth & -.03 & .13 & & -.12 & .14 & & .21 & .13 & & -.28 & .13 & $* *$ & -.26 & .15 & $*$ & -.01 & .14 & \\
\hline Pay Fees & .04 & .15 & & .02 & .14 & & -.09 & .14 & & .21 & .14 & & .01 & .16 & & .05 & .16 & \\
\hline Form $2^{1}$ & .91 & .43 & $* *$ & .09 & .41 & & -.35 & .43 & & .71 & .40 & $*$ & -1.02 & .48 & $* *$ & -.75 & .46 & \\
\hline${\text { Form } 3^{1}}^{1}$ & -.19 & .40 & & -.10 & .39 & & -.46 & .41 & & .10 & .39 & & -.46 & .46 & & -.83 & .44 & $*$ \\
\hline Form $4^{1}$ & -.02 & .43 & & .12 & .41 & & -.51 & .41 & & .29 & .40 & & -1.04 & .47 & $* *$ & -.82 & .45 & $*$ \\
\hline Religion & .11 & .26 & & .45 & .26 & $*$ & -.33 & .26 & & .35 & .26 & & -.04 & .28 & & -.10 & .29 & \\
\hline Guardian & -.07 & .25 & & .24 & .25 & & .26 & .25 & & -.11 & .25 & & -.03 & .27 & & .30 & .28 & \\
\hline Polygamy & -.54 & .33 & & -.33 & .32 & & .55 & .32 & $*$ & -.07 & .31 & & .42 & .36 & & .30 & .36 & \\
\hline /cut1 & -2.29 & .44 & & -1.27 & .40 & & -1.50 & .40 & & -1.03 & .40 & & -4.38 & .71 & & -4.11 & .70 & \\
\hline /cut2 & -.85 & .40 & & .11 & .38 & & -.35 & .39 & & .54 & .39 & & -3.36 & .54 & & -3.24 & .55 & \\
\hline /cut3 & -.29 & .40 & & .82 & .38 & & .09 & .39 & & 1.18 & .39 & & -1.44 & .44 & & -1.55 & .44 & \\
\hline /cut4 & 1.10 & .40 & & 1.56 & .39 & & 1.30 & .40 & & 2.08 & .41 & & .26 & .43 & & .16 & .42 & \\
\hline $\mathrm{N}$ & 242 & & & 242 & & & 244 & & & 244 & & & 242 & & & 244 & & \\
\hline
\end{tabular}

Table 3 reveals that students from the Academy are more likely to believe that the lifestyles they see on American TV programs accurately represent how life is lived; that racism is not a problem in the US today; that Americans would not judge them based on their skin color; and that it is easy to find jobs in America. They also have a more positive overall view of American people and are more likely to consider the US a good place to live. The odds ratios range from a high of 3.3 for a positive view of American people, to a low of .66 for believing that racism is not a problem in America.

Lastly, in Table 4 we explore four responses that measure aspects of perceptions of relative deprivation. The first three are ordered logit models. We find that Academy students are more likely to agree that seeing the wealth of mzungus (Westerners) makes them think about material things that they want but do not have $(\mathrm{OR}=1.69)$. In contrast, we see no differences between the groups with the statement "I am not happy or fulfilled because I need more money" or the statement "I have all the material things I need to be happy in life." The fourth is a logit model for the outcome that measures preference for Western vs. Kenyan culture. Table 4, Model 4 shows that Academy students are more likely to say that they favor Western culture over Kenyan culture (OR $=1.97)$.

Table 4. Ordinal logit and logit models for measures of relative deprivation.

\begin{tabular}{|c|c|c|c|c|c|c|c|c|c|c|}
\hline \multirow[b]{3}{*}{ Academy (v } & \multicolumn{3}{|c|}{ Muzungu Wealth ${ }^{2}$} & \multicolumn{2}{|c|}{ Lack Money $^{2}$} & \multicolumn{2}{|c|}{ Have Material $^{2}$} & \multicolumn{3}{|c|}{$\begin{array}{l}\text { Western or Kenyan } \\
\text { Culture }^{3}\end{array}$} \\
\hline & $\mathrm{B}$ & SE & & B & SE & B & SE & B & SE & \\
\hline & & & \multirow{3}{*}{$* *$} & & & & & & & \\
\hline Control) & .53 & .25 & & .18 & .25 & -.31 & .25 & .68 & .30 & $* *$ \\
\hline E-media & .35 & .32 & & -.19 & .32 & -.27 & .32 & .78 & .39 & $* *$ \\
\hline $\mathrm{TV}$ & .13 & .15 & \multirow{3}{*}{$* *$} & -.11 & .15 & .00 & .14 & .13 & .17 & \multirow{3}{*}{$* *$} \\
\hline Wealth & -.27 & .14 & & -.12 & .13 & .45 & .14 & -.42 & .17 & \\
\hline Pay Fees & -.15 & .15 & & -.05 & .14 & .23 & .15 & -.19 & .18 & \\
\hline
\end{tabular}




\begin{tabular}{|c|c|c|c|c|c|c|c|c|c|c|c|}
\hline Form $2^{1}$ & -.28 & .43 & & .13 & .43 & & -.30 & .44 & -.43 & .54 & \\
\hline Form $^{1}{ }^{1}$ & -.64 & .43 & & -.07 & .41 & & -.25 & .42 & -.19 & .51 & \\
\hline Form $4^{1}$ & -.94 & .45 & $* *$ & .75 & .44 & $*$ & -.62 & .43 & .35 & .51 & \\
\hline Religion & .07 & .27 & & .25 & .27 & & .12 & .27 & .05 & .32 & \\
\hline Guardian & .00 & .26 & & -.13 & .25 & & -.33 & .26 & -.19 & .32 & \\
\hline Polygamy & .02 & .33 & & .20 & .33 & & -.06 & .33 & .23 & .39 & \\
\hline constant & & & & & & & & & -1.03 & .49 & $* *$ \\
\hline /cut1 & -1.80 & .42 & & -.59 & .40 & & -1.76 & .42 & & & \\
\hline /cut2 & -.73 & .41 & & .83 & .40 & & -.50 & .41 & & & \\
\hline /cut3 & -.65 & .41 & & .98 & .40 & & -.33 & .41 & & & \\
\hline /cut4 & .34 & .41 & & 1.83 & .42 & & .53 & .41 & & & \\
\hline $\mathrm{N}$ & 240 & & & 241 & & & 241 & & 235 & & \\
\hline
\end{tabular}

\section{Discussion}

Despite recent calls to the contrary, research on ISL has focused almost exclusively on learning outcomes for global North students. We know comparatively less about how ISL programs may impact the knowledge and perceptions of student participants from host countries in the global South. Our study represents an initial foray into these questions by examining learning outcomes for Kenyan students who interact with visiting students from a U.S. university. Specifically, using an original survey and a case-control design, we compare the responses of students from a partner school in rural Kenya, the Academy, with students in a similarly situated control school to explore how program participation influences ideas about global citizenship, viewpoints about America, and feelings of relative deprivation.

Results point to the complexity of ISL programs and their impact on host participants. On the one hand, we find that Academy students show greater levels of global citizenship than students in the control group. Academy students are more likely to agree that they are comfortable interacting and making friends with individuals from other countries, as well as more likely to agree that they can see the world through someone else's eyes and respect different cultural values and practices. These results indicate support for a major goal of the program: to augment skills in relationship building and the development of cross-cultural perspectives. Survey results also corroborate observations from previous interviews with Academy students and Kenyan program leaders who often express how meeting and working with Western students enhances their cross-cultural orientation, honing skills that are highly valued in Kenyan society and considered cornerstones of global citizenship. An alternative explanation could be that Academy students are more likely to answer these specific questions positively due to their exposure to the language used by U.S. students, and therefore their responses may not represent core beliefs. This is a limitation that further study could investigate. However, even if this were the case, familiarity with global citizenship language might be considered an encouraging first step towards the development of beliefs and practices.

On the other hand, survey results indicate that intercultural exposure through ISL may also facilitate less desirable learning outcomes for Academy students. In addition to increased cross- 
cultural understanding, a central question in ISL research is how intercultural contact shapes knowledge and stereotypes about cultures. Indeed, one of the program objectives is mutual colearning about each respective society, which includes dispelling Pollyanna myths about social and economic life in the US. We assess the effectiveness of this goal by comparing Academy and control group students' agreement with 11 stereotype measures and two measures about general life in the states. While most (7 out of 11) of the between-group differences in the stereotype measures are not statistically significant, we find that Academy students are actually more likely than the control group to agree with unrealistically positive views of America in four stereotype measures. Two of the stereotypes relate to racism (that it is not a big problem in America today and that Americans would not judge survey respondents based on skin color), one to media (the lifestyles represented on American TV programs are realistic), and one to jobs (they are easy to obtain in the US). Two additional survey questions record respondents' views of American people and of America as a place to live. Here again, Academy students are much more likely than the control group to hold favorable views. Our study thus suggests that, in spite of making a concerted effort to dispel stereotypes, Academy students appear to hold to some of them more strongly.

We suggest that Allport's theory of group contact provides some insight into these findings. Allport's thesis highlights the promise of intergroup contact for challenging misinformation about outgroups when four important conditions are met. Although the program strived to meet the four conditions (equal status, support from social and institutional leadership, working together on common goals, in a cooperative environment), ascribed asymmetrical statuses based on global hierarchies are not easily overcome. In the end, American students, particularly those who find a way to study abroad, represent a global elite. Some research indicates that intergroup contact between groups of asymmetrical status can actually exacerbate misinformation (Pettigrew \& Tropp, 2005). In this case, Academy students' lived experience with American students is likely more impactful than hearing Americans describe social problems in the abstract. It has been previously suggested that ISL has the potential to reinforce the very attitudes that it is designed to challenge, particularly related to the belief that the global South represents poverty while the global North represents wealth (Crabtree, 2013). We find some evidence to suggest this may be occurring.

A related consequence of intercultural contact between groups of unequal status is the risk of enhanced perceptions of relative deprivation. Academy students report significantly higher responses on two of four items that measure relative deprivation. Academy students are more likely to say that Western culture is better for most people and to agree with the statement that seeing the wealth of Westerners makes them think about things they want but do not have. These findings lend support to the concern that program participation may lead Kenyan students to adjust their selfreference to include socio-economically privileged students from the global North. ${ }^{\text {vi }}$

Our survey results lead us to suggest that ISL leaders proceed with caution and further consider how to mitigate potential negative impacts. One area for deeper investigation relates to U.S. students' reckoning with their relative status. In our own and other program leaders' experiences (Larkin, 2015), students from the global North are often uncomfortable coming to terms with their privilege. For example, we have observed our students develop elaborate ways to explain their impoverished student-status to community partners in an attempt to manage the discomfort they experience when partners marvel over their wealth. Such attempts to resist socio-economic difference may signal a 
desire for Western students to maintain a position of innocence or neutrality in global hierarchies (Larkin, 2015:152), consequently burying unjust inequities. In contrast, this discomfort may be a motivation to reformulate relationships. We support calls to initiate deeper exploration of difference, particularly in a manner that does not re-inscribe Western hierarchies or solutions (Crabtree, 2013; Larkin, 2014 \& 2015). Perhaps a step forward can be engaging in these discussions openly with the community.

Our study points to both the promises and challenges of ISL programs. Although our study was designed over time with the benefit of a long-term, collaborative partnership, our present findings are based on a survey conducted on a single program at a single point in time and thus represent an initial, and therefore limited, attempt to assess the impacts of ISL on a host community. Much more empirical work is necessary to understand the complex processes set in motion by education in an intercultural context. For one, future inquiry should endeavor to unpack the mechanisms that link intercultural contact with learning outcomes. We employ a classic theory that highlights the importance of contact for improving the quality of information and communication between groups (Allport, 1954), yet we are unable to elucidate precisely how intercultural contact influences intergroup knowledge formation. We also acknowledge that community members participate in and are attached to ISL programs at varying levels. In this case, variation in the number and intensity of relationships formed by host students may also influence intercultural learning. Here, more detailed qualitative research may better illuminate how the quantity and quality of contact might moderate intercultural learning processes. Furthermore, pre-post and longitudinal research designs could provide more insight into how ideas about global citizenship, knowledge of other cultures, and perceptions of deprivation change before, during, and after participation in ISL programs.

We have focused on a limited set of important outcomes, yet the potential impacts to host communities extend well beyond ideas about global citizenship or perceptions of deprivation. Additional areas of inquiry include the myriad social, psychological, and cultural impacts of interaction, as well as the consequences of ISL programs for economic and educational development. Importantly, research should strive to represent the interests of host communities. Research focused on Western-based theories and methodologies admittedly risks furthering hegemonic assumptions about objectivity, knowledge, and truth (Larkin, 2016). Community Based Participatory Research (CBPR) could be employed to identify and assess outcomes valued by the community and help define collaborative research agendas.

Furthermore, as ISL programs differ widely in their conceptualization, design, and particulars, it is quite difficult to generalize the results of a study that focused on one program. Our program is a based on a very collaborative, long-term partnership, which arguably enhances the potential impact of intercultural contact. It is not immediately clear how our findings would alter if the program were less collaborative or based on less-established partnerships. Additionally, the fact that a program faculty member also designed and helped implement the survey could influence the results. For example, it is possible that students may have felt pressured to respond positively to items about life in the United States. To address this possibility, we clarified to the student participants that their surveys were anonymous and that there were no right answers. We also note that we do not find the results surprising, given years of experience and conversations with the Academy students that 
mirrored the survey responses. Nonetheless, some caution is warranted when attempting to generalize from our study to other contexts. As scholars continue to heed the call to study ISL and build an empirical base on which to found theory about the factors that shape impacts on host communities and beyond, it will be important to assess how various aspects of program design and implementation influence outcomes. We look forward to engaging with these questions in future research and hope that this is just a first step towards conducting quantitative analysis of program impacts.

\section{Conclusion}

We provide preliminary empirical evidence to suggest that while program participation can lead to positive outcomes for community partners, it may also produce unintended consequences related to the perpetuation of global scripts that denigrate the global South vis-à-vis the global North and exacerbate perceptions of relative deprivation. The extensive thought and recommendations of GSL best practices have resulted in more interconnected, holistic programs that expose and explore assumptions about power and privilege and focus on collaborative learning as a means to work towards ethical engagement. Yet in spite of programs that do their best to follow GSL goals and codes of conduct, the relationships we build across cultures exist both within and against global structures of inequality that are rooted in historic injustices.

Should the fact that we cannot eliminate global inequality keep us from pursuing deep relationships in ISL partnerships? We suggest no; rather, we believe such relationships may help to generate the commitment and passion necessary to push against seemingly intractable power structures. Although it is admittedly impossible to eliminate all unintended consequences, our own unpublished evaluation research and other studies suggest that, when asked, communities want programs to continue (Kozak and Larsen, 2016). And the multifaceted benefits of ISL to Western students are well-documented. We call on future research and program design to attend deeply to global positionality inherent in cross-cultural relationship formation. Focusing on imbalance in relationship and acknowledging our discomfort with it may reveal insights into identifying effective strategies to address inequities and make ISL programs more accountable to communities.

\section{Acknowledgements}

We extend our deepest gratitude to the members of the Kenyan community with which we have partnered for many years and to the students at the Academy who agreed to participate in this study. We also extend thanks to our Kenyan colleague who helped us establish a relationship with a control group school and to the students at that institution for their participation. This research was approved by the Western Washington University Office of Research and Sponsored Programs.

\section{Endnotes}

i Secondary school is equivalent to a four-year U.S. high school, and classes are referred to as Forms, advancing from Form 1 (Freshman) to Form 4 (Senior).

ii A Kenyan colleague helped arrange our contact with the control school.

iii As a former British colony, Kenyan schools are taught in English, and secondary students are fluent speakers.

${ }^{\text {iv }}$ Before being administered, the survey was piloted with two community cultural liaisons and a small sample of students from the Academy. Pilot testing resulted in three sets of survey revisions.

${ }^{v} 66.4$ percent of the students in the sample identify as Seventh Day Adventist Christians. Another 29.4 percent of the sample identify as another Christian denomination (Catholic, other), 2.7 percent identify as Muslim, and 1.6 identify either as another or no religion. 
${ }^{\text {iv }}$ Although these results suggest that the Academy students' relationships with American students are associated with greater feelings of deprivation, we caution that their recognition of global inequities may not translate to greater unhappiness. Academy and control school students do not differ significantly in the remaining two relative deprivation measures that focus on happiness related to money or material things. Furthermore, if anything, Academy students appear to be more satisfied with their circumstances. The full survey includes 17 questions related to self-esteem, self-efficacy, and happiness. In supplemental analyses (available upon request), we find that just three of these items vary significantly across groups, namely I love myself; I feel that I can make a difference; and I am satisfied with my future choices. For each of these three statements, Academy students are significantly more likely than control school students to agree.

\section{References}

Allport, G. W. (1954). The Nature of Prejudice. Cambridge, MA: Perseus Books.

Arends, J. (2016). In the right relationship: A case study of international service learning in eastern Africa. In M. A. Larsen (Ed.), International service learning: Engaging host communities (pp. 108-118). New York, NY: Routledge.

Baldwin, T., Mohamed, S., \& Tembe, J. (2016). The potential of ISL: Re-examining ethical engagement amongst ISL partners. In M. A. Larsen (Ed.), International service learning: Engaging host communities (pp. 201-214). New York, NY: Routledge.

Bortolin, K. (2011). Serving ourselves: How the discourse on community engagement privileges the university over the community. Michigan Journal of Community Service Learning, 18(1), 49-58.

Bringle, R. G., \& Hatcher, J. A. (2011). International service learning. In R. G. Bringle, J. A. Hatcher, \& S. G. Jones (Eds.), International service learning: Conceptual frameworks and research (pp. 3-28). Sterling, VA: Stylus.

Crabtree, R. D. (2013). The intended and unintended consequences of international service-learning. Journal of Higher Education Outreach and Engagement, 17(2), 43-66. Retrieved from https://works.bepress.com/robbin_crabtree/14/

Dear, S., \& Howard, R. (2016). Many meanings: Moving reciprocity towards interdependence. In M. A. Larsen (Ed.), International service learning: Engaging host communities (pp. 162-174). New York, NY: Routledge.

Fry, G. W., Paige, R. M., Jon, J. E., Dillow, J., \& Nam, K. A. (2009). Study abroad and its transformative power. CIEE Occasional Paper, 32, 1-72.

Galiardi, S., \& Koehn, J. (2012). Strategies to mitigate the negative and accentuate the positive impacts of international service-learning on host communities. Partnerships: A Journal of Service-Learning and Civic Engagement, 2(1), 1-12. Retrieved from http://libjournal.uncg.edu/prt/article/view/431

Hartman, E., \& Kiely, R. (2014a). A critical global citizenship. In P.M. Green \& M. Johnson (Eds.), Crossing boundaries: Tensions and transformation in international service-learning (pp. 215-242). Sterling, VA: Stylus.

Hartman, E., \& Kiely, R. (2014b). Pushing boundaries: Introduction to the global service-learning special section. Michigan Journal of Community Service Learning, 21(1), 55-63.

Hartman, E., Paris, C. M., \& Blache-Cohen, B. (2014). Fair trade learning: Ethical standards for community-engaged international volunteer tourism. Tourism and Hospitality Research, 14(1-2), 108-116. doi:10.1177/1467358414529443

Hernández, J. (2016). Reflections from a Nicaraguan career ISL program coordinator: Challenges and guidelines for moving forward. In M. A. Larsen (Ed.), International service learning: Engaging host communities (pp. 147-161). New York, NY: Routledge.

Heron, B. (2016). Southern perspectives on ISL volunteers: Reframing the neo-colonial encounter. In M. A. Larsen (Ed.), International service learning: Engaging host communities (pp. 94-107). New York, NY: Routledge.

Hyman, H. H., \& Singer, E. (Eds.) (1968). Readings in reference group theory and research. New York, NY: The Free Press. 
Jorgenson, S. (2016). Orient(aliz)ation: A case study of North American international education programs at the University of Ghana. In M. A. Larsen (Ed.), International service learning: Engaging host communities (pp. 119-130). New York, NY: Routledge.

Kiely, R. (2005). A transformative learning model for service-learning: A longitudinal case study. Michigan Journal of Community Service Learning, 12(1), 5-22.

Kiley, R. (2011). What international service learning research can learn from research on international learning. In R. G. Bringle, J. A. Hatcher, \& S. G. Jones (Eds.), International service learning: Conceptual frameworks and research (pp. 243-273). Sterling, VA: Stylus.

Kozak, J., \& Larsen, M. (2016). Conclusion: ISL and host communities-relationships and responsibility. In M. A. Larsen (Ed.), International service learning: Engaging host communities (pp. 263-276). New York, NY: Routledge.

Larkin, A. (2015). Close encounters of the other kind: Ethical relationship formation and international service learning. Citizenship Teaching and Learning, 10(2), 143-155. doi:10.1386/ctl.10.2.143_1

Larsen, M. (2014). Critical global citizenship and international service learning: A case study of the intensification effect. Journal of Global Citizenship \& Equity Education, 4(1),1-43.

Larsen, M. (2016). International service learning: Engaging host communities. In M. A. Larsen (Ed.), International service learning: Engaging host communities (pp. 3-18). New York, NY: Routledge.

Lutterman-Aguilar, A., \& Gingerich, O. (2015). Experiential pedagogy for study abroad: Educating for global citizenship. Frontiers: The Interdisciplinary Journal of Study Abroad, 8, 41-82.

MacDonald, K., \& Vorstermans, J. (2016). Struggles for mutuality: Conceptualizing hosts as participants in international service learning in Ghana. In M. A. Larsen (Ed.), International service learning: Engaging Host communities (pp. 131-146). New York, NY: Routledge.

Merton, R., \& Kitt, A. (1950). Contributions to the theory of reference group behavior. Glencoe, IL: Free Press.

Nelson, E., \& Klak, T. (2012). Equity in international experiential learning: Assessing benefits to students and host communities. PRISM: A Journal of Regional Engagement, 1(2), 106-129. Retrieved from http://encompass.eku.edu/prism/vol1/iss $2 / 3$

O'Sullivan, M., \& Smaller, H. (2016). Solidarity or neo-colonialism? The challenges of understanding the impact of ISL on Nicaraguan host communities. In M. A. Larsen (Ed.), International service learning: Engaging host communities (pp. 49-64). New York, NY: Routledge.

Paik, S. J., Ganley, D. E., Luschei, T. F., Kula, , S. M., Witenstein, M. A., Shimogori, Y., Truong, K. K. (2015). Intercultural exchange among global teachers: The case of the teaching excellence and achievement study abroad program. International Journal of Intercultural Relations 49, 100-113. doi:10.1016/j.ijintrel.2015.06.011

Pettigrew, T. F., \& Tropp, L. R. (2006). A meta-analytic test of intergroup contact theory. Journal of Personality and Social Psychology, 90(5), 751-783. doi:10.1037/0022-3514.90.5.751

Reynolds, N. P. (2014). What counts as outcomes? Community perspectives of an engineering partnership. Michigan Journal of Community Service Learning, 21(1), 79-90.

Rutstein, S. O., \& Johnson, K. (2004). The DHS wealth index. DHS Comparative Reports No. 6. Calverton, Maryland: ORC Macro.

Schroeder, K., Wood, C., Galiardi, S., \& Koehn, J. (2009). First, do no harm: Ideas for mitigating negative community impacts of short-term study abroad. Journal of Geography, 108(3), 141-147. doi:10.1080/00221340903120866

Smedley, C.T. (2016). The economic circle: Impacts of volunteerism and service learning on three rural communities in Costa Rica. In M. A. Larsen (Ed.), International service learning: Engaging host communities (pp. 65-79). New York, NY: Routledge.

Tarrant, M. A., Rubin, D. L., \& Stoner, L. (2015). The effects of studying abroad and studying sustainability on students' global perspectives. Frontiers: The Interdisciplinary Journal of Study Abroad, 26, 68-82. 
Tarrant, M. A., Rubin, D. L., \& Stoner, L. (2014). The added value of study abroad: Fostering a global citizenry. Journal of Studies in International Education, 18(2), 141-161. doi:10.1177/1028315313497589

Tonkin, H. (2004). Service learning across cultures: Promise and achievement. New York, NY: International Partnership for Service-Learning and Leadership.

Whitehead, D. M. (2015). Global service learning: Addressing the big challenges. Diversity and Democracy, 18(3). Association of American Colleges and Universities. Retrieved from https://www.aacu.org/diversitydemocracy/2015/summer/whitehead

Wood, C., Banks, S., Galiardi, S., Koehn, J., \& Schroeder, K. (2011). Community impacts of international service-learning and study abroad: An analysis of focus groups with program leaders. Partnerships, $2(1), 1-23$. 